\title{
The Strategic Nature of the Employment Relationship
}

\author{
Elijah Kimeu Chen Zhixia \\ College of Public Administration, Huazhong University of Science and Technology, Wuhan, China Wuhan, \\ China\# 1037 Luoyu Road, Wuhan 430074, P. R. China
}

\begin{abstract}
The strategic nature of employment relationship provides HRM professionals with information and direction that culminate into understanding, evaluating, and applying current thinking regarding the new employment relationships. In the current days, academic researchers have more and more extension with regard to the modern organizational dynamics. The significant focal point of this article is an examination concerning the degree to which there is an agreement in empirical literature in regard to strategic nature of employment relationship by procedurally evaluating the substance of applicable and comparable articles. The discussion herein integrates empirical conclusions from other studies, interprets the similitude and contrasts between the articles against those established in corporate period publications, thereby providing conclusions for the modern Human resource experts while also, suggesting areas of improvement for the modern business organizations.
\end{abstract}

Keywords: Human resource practices, Strategic nature of employment relationship, Employer, psychological contract, organizations.

DOI: $10.7176 / \mathrm{EJBM} / 11-12-15$

Publication date: April $30^{\text {th }} 2019$

\section{Introduction}

Recurrent and continuous changes have invariably reshaped organizations and the idea of work itself. The components of globalization and unnecessary competition; the quickly extending scope of conceivable outcomes and opportunity of decision making for people, networks, and social orders; and the developing intricacy of specialized and social associations are only a portion of the elements that expect organizations to persistently adjust their technique and plan. In the recent past, authoritative researchers anticipated an eventual fate of natural smoothness in hierarchy. The idea of hierarchical smoothness alludes to a firm's capacity to act advantageously with its condition. Organizations mostly invest their available resources into human resource practices like promotions, training and development, motivations, only to enhance these relations. There seems, by all accounts, that because of changes in the financial and social conditions in which organizations operate, the nature of the industrial relations is experiencing major changes that have essential ramifications for employment relationships. A psychological contract supports the employment relationship and is seen as an arrangement of unwritten desires that exist among workers and their bosses. It is for the most part acknowledged that a psychological contract is worrying about a person's emotional convictions, molded by the association concerning the terms of contract between the individual representative and the entity. A psychological contract administers the proceeding with advancement of the employment relationship which develops after some time, with the desires for the gatherings appearing as implied suspicions that call for dialogue and concurrence with people and groups. The employment relationship has turned out to be more of clearing a path for different sorts of nontraditional employment connections, for example, low maintenance, transitory, adaptable, virtual, triangular, and contract work, to give some examples (Alcover et al., 2016) .

Social exchange theory contributes in a way, to the conceptual development of variables that incarcerate the employee organization exchanges, not excluding the psychological contract (PC), perceived organizational support (POS), organization trust, and leader vs employee exchange. On the other hand, there exists wide-ranging pragmatic verification that these kinds of exchange constantly preempt a many occupational behaviors, such as recognition, obligation, psychological attachment, faith, job satisfaction, intent to leave the organization, organizational citizenship behavior, and exertion effort and on the job performance. And especially in such times of downturn, austerity measures on human resource practices are very vital. With an effort of validating which human resource practices play important roles in nurturing psychological contracts with the particular subordinates, this paper could assist to determine the strategic nature of employment relationship in the modern world.

\subsection{Defining psychological contract}

Psychological contracts imply the values that individuals hold about assurance that others promise and of which they consent and be dependent on. In organizations, such contracts are not limited to employers' and employees' hope on one another. They give information into troubles about employment connections and the ramifications of these challenges on individual and hierarchical conduct. The contracts are the arrangement of desires held by the individual worker which determines what the individual and the organization hope to provide for and get from one another over that time of their working relationship. 
As indicated by Epitropaki, (2013), a psychological contract is all about the impression of the two components to the employment relationship; organization and individual, of the equal guarantees and commitments inferred in that relationship. It a system of convictions that envelops the activities that workers accept is anticipated from them and what reaction they expect consequently from their supervisors and, correspondingly, the activities businesses accept are anticipated from them and what reaction they expect from their employees. It is the convictions in view of guarantee communicated or suggested in regards to an exchange understanding between an individual and, in organizations, the utilizing firms and its specialists. These convictions rise above the composed and express arrangements of the formal employment contract (Chew \& Chan, 2008).

A three-tier model of the psychological contract was developed and pegged on an extensive empirical research and the influence of reorganization of the psychological contract for the respective managers that were evaluated. It was confirmed that, at the lowest cadre, employees were understood to create bearable amounts of demands and accountability for example logical time limits, convenient workload, average stress, commensurate independence, levelheaded span of control, controllable duty variation and enough accountability in return for suitable rewards for instance commensurate level of pay, viable work environments, employment satisfaction and the chance to display capability; all these are termed as transactional component of the psychological contract. The second type of the psychological contract refers to the exchange of commitment to (the tasks assigned, the relevant department, and to the organization at large) on behalf of the subordinate in anticipation for career progression and/ or training and development to enhance the ability to be employed in other organizations. The model also projected that the subordinates at the relational level will have and show loyalty and confidence in the management as a retaliation for a better and able administration, the opportunity to exercise too, decision making and team spirit that ideally portray some originality.

Psychological contracts can be seen as containing both relational and transactional angles (Rousseau, 1990). Transaction contracts are of a restricted span with very much specific performance terms. It is available when the employment plan is for a present moment, basically centered on trade of work in lieu of cash with a particular and positive depiction of obligations and duties and restricted inclusion in organizations. This is especially valid for employees enlisted on short contracts just as laborers situated off-site (Kraatz and Rousseau, 1994 referred to in Katou, 2012).

As indicated by Maigure (2002) changes in the transactional terms of the contract can impact the sorts of relational prizes expected or commitments seen by the employees. For instance, when an employee is given additional undertakings or more upsetting work without extra remuneration or expanded prospects of advancement, this is probably going to be viewed as a negative move in the transactional part of the worker's psychological contract. There might be little he/she can do to address the lopsidedness in regard to transactional things. For instance, should workers be enticed to diminish exertion or performance level to decrease the awkwardness, this may be a demonstration to decline the circumstance. It is likely, in such a circumstance, that workers will pull back a few or the majority of their commitment to the relational part of the psychological contract by diminishing duty, unwaveringness or trust in administration. It is this interactivity between transactional and relational components of the psychological contract which can possibly bring up issues for organisations in the midst of organizational change (Maigure, 2002).

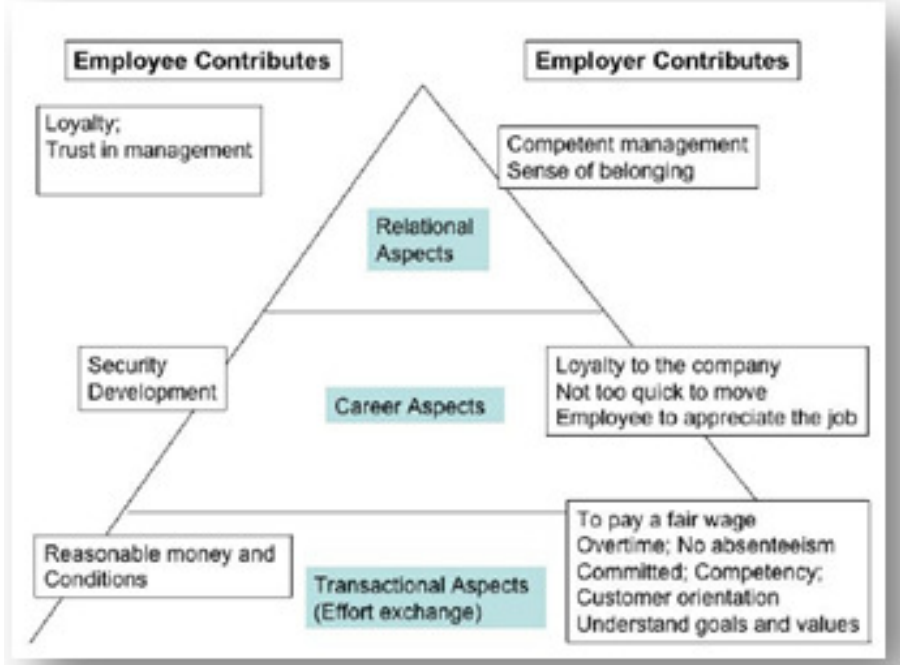

Figure 1.1 shows the three-tire model of the psychological contract as studied by Maigure (2002).

\section{Methodology}

The study embraced documentary analysis technique to collect contents of relevance. Wide arrays of documents 
were gathered, while considering the subjectivity of the author and furthermore the individual predispositions he or she might bring to the research. The study also considered whether the author was a firsthand witness or used second-hand sources. The information so garnered was then organized into what is related to central questions on the strategic nature of employment relationship (Bowen, 2009). Since different studies give diverse findings to a content analysis study with a similar research question ( Roehling, 1998), varied methods that embraces both qualitative and quantitative studies were embraced in the combination as recommended by Rupp, et al., (2014). Any publication that was theoretical in intent and also supported by empirical studies, was not isolated either.

The study depended on documents analysis in light of the fact that the technique is a proficient and successful method for gathering data since reports are manageable and practical resources. Acquiring and analysing documents is frequently significantly more cost proficient and time effective than leading your very own examination or trial, in addition, they are non-receptive information sources; can be perused and looked into different occasions and stay unaltered by the scientist's impact or research process. The relevant data for the study was retrieved from relevant publications, books of human resource specialty in library, online journals, articles, and computer search engines like Google scholar, Google, Sage and Emerald. As a first step, the study conducted a straightforward search in employment relationship databases specifically using rational arrangement of such key words as: Human resource practices, Strategic nature of employment relationship, Employer, psychological contract, organizations.

Secondly, the study refined the search by embracing the terms revealed in the initial search and managed to retrieve several publications and books. The study however, eliminated those that appeared subjective and inconsistent in findings. Some also looked selective and incomplete, culminating into a good number of publications and books that looked closely relevant and suitable for content analysis in terms of process criteria. Finally, we settled to items that were very appropriate for review and analysis and so they were summarized on a model and then used for citations and referencing. The relevant publications and books were then analysed quantitatively to establish the strategic nature of employment relationship.

The main key areas for employment relationship was established as confirmed by (Maigure, 2002) on his three-tier model of the psychological contract, then expanded the content as cited in the article of Rousseau (2004), on Psychological Contracts in the Workplace. This culminated into a further analysis on causes and consequences of the psychological contract which was grounded on systems theory, social exchange theory and strategic choice theory. Employment relationship was further analysed by looking into the strategic nature of psychological contracts and how human resource practices affect psychological contacts.

\section{Theoretical Argument}

This paper was grounded on system theory, strategic choice theory and social exchange theory.

\subsection{Systems theory (John Thomas Dunlop, 1958)}

Systems theory is a substitute perspective to comprehending, managing and planning employment relationships. The theory holds that industrial relations are best perceived as a component of the bigger communal framework. The theory holds work to be represented by an extensive variety of formal and casual rules and directions, which cover everything from enlistment, occasions, execution, wages, hours, and a bunch of different points of interest of employment. It attests that these rules are what industrial on-screen characters endeavor to decide, that their foundation is impacted by the more extensive ecological setting in which the on-screen characters work, and that the performers themselves share an enthusiasm for keeping up the procedures of arrangement and compromise. On the back of these affirmations four components are held to make up the system of industrial relations lead making. The first is industrial on-screen characters, which comprises of bosses and their agents (i.e., business affiliations), employees and their delegates (like trade unions), and outer organizations with an enthusiasm for industrial relations (like the Government divisions and work courts). The second is the ecological setting, which comprises of winning financial and innovative conditions, and also the circulation of intensity in more extensive society, every one of which is thought to impact or compel the activities of on-screen characters occupied with industrial relations. The third is a supposed 'web of rules' that administers the employment connection dispatch and is held to be the result of cooperation between the performing artists. The latter is a 'binding ideology', which is an arrangement of regular convictions and understandings that serve to empower bargains with respect to every on-screen character for making the system operable.

\subsection{Strategic choice theory}

Strategic choice theory is only a re-invention of the systems theory propounded by Dunlop (1958) and enhanced the later by including some modern changes in the perspective from which employment relations was practiced in the olden times. Three of the improvements are well-known to be significant in shaping the way supervisors handle employment relations matters. An imperative element of this theory is that it perceives the interrelationship among choices and exercises crosswise over various levels of the industrial relations system. Along these lines, a choice 
taken at the vital level to present new technologically enhanced capital hardware will more likely than not have implications for the lead of aggregate haggling over future preparing and keeping an eye on levels, and additionally for the direct of working environment relations if keeping an eye on levels are to be changed or occupations revamped. The theory likewise recognizes the impacts of key choices on various different elements in the system. Strategic changes embraced by the respective state to macroeconomic strategies, like for example, may adversely affect an organization's long-term venture strategy, and especially in the case where it perceives that such changes may influence bank interest rates. Incase its convincing that the rates will be inflated hence reducing the need to uphold the current human resource levels, then obviously, it will have a negative aftermath to the entity's prospective employment policies, human resource policies, aggregate bargaining, and nature and lead of employment relations in the work environment.

\subsection{Social exchange theory}

Social exchange theory is mostly utilised in the business world to articulate and synthesize business dealings. The theory of social exchange perceives people interactions and dealings as results-driven social behaviour. The central idea of the theory of social exchange is cost and rewards. This implies cost and reward examinations drive human choices and conduct. Expenses are the negative outcomes of a choice, for example, time, cash and vitality. Prizes are the positive consequences of social exchanges. Subsequently, the by and large acknowledged thought is that individuals will subtract the expenses from the prizes keeping in mind the end goal to figure the esteem.

The theory of social exchange suggests that people will settle on choices in view of specific results. For instance, they will expect the most profit, rewards, positive results and long haul benefits. They will likewise prefer the exchange that directs towards utmost security, social endorsement and autonomy. Interestingly, they will likewise pick choices that outcome in the least costs, results and minimum social dissatisfaction. Hence, every social exchange choice like employment relationships can be a mind boggling choice that requires the individual to assess distinctive expenses and rewards. Along these lines, social exchange theory gives an intense structure to understanding work environment exchanges and relationships. Its informative esteem depends on the essential fundamental that social exchanges contain activities that are dependent upon the compensating responses of others. Suggested is a common procedure whereby exchanges or exchanges may encourage quality relationships. In total, social exchanges make interlocking status obligations that at last start, keep up, and balance out social practices both inside and outside associations.

\section{Empirical Review}

In this section, we reviewed the limited research on the strategic nature of the employment relationship. From here, we look beyond the strategic nature of the employment relationship to examine what the literature suggests on the key aspects of employment relationship from strategic nature of psychological contract to causes and consequences of the psychological contract, the new employment relationship, psychological contract breach, and the relationship between Human resource management practices and psychological contract.

\subsection{Causes and Consequences of the psychological contract}

Epitropaki (2013) alluded that in the modern times, pressure on the public segment entities to offer lofty quality, customer oriented services is a must have. This has culminated into vast activities being taken by the general population area to enhance its performance. As far as personnel management this prompts an expanded enthusiasm for, among others, performance management, performance pay, skill structures, employee and director assessment. To an ever increasing extent (human asset) rehearses that used to have a place with the private segment are being presented out in the open area management. Open hirelings appear to have higher desires than specialists in different parts they frequently have a solid psychological contract, particularly in the event that they are exceedingly taught. They also have a devoted psychological contract, setting accentuation on Long term inclusion (Freese and Schalk 2008). Reasonable and individual treatment, nature of treatment and data on changes influencing employees are additionally guaranteed all the more frequently in general society segment. Contrasted with the private area, open segment specialists encounter all the more frequently a break in their psychological contract. Ceaseless and vast scale change endeavors and join enormous guarantees by management have driven especially in focal government to (as well) exclusive requirements in the brains of employees. It appears that management can't convey what they have guaranteed (Jones and Skarlicki, 2013).

The psychological contract is impacted by an entire scope of variables, both individual and authoritative. The psychological contract likewise has its impact on a scope of states of mind and practices. There is a positive connection among interest and the satisfaction of the psychological contract. Authoritative change can likewise detrimentally affect the condition of the psychological contract. Leonardelli, et al (2010) confirmed in their study on optimal distinctiveness theory: A framework for social identity, social cognition, and intergroup relations. Individual and social background factors are additionally conceivable impacts for the psychological contract. Great psychological contract may not generally result to prevalent performance, or for sure to fulfilled employees yet 
poor psychological contracts tends to go about as de-sparks, which can be reflected in bring down levels of employee responsibility, more elevated amounts of non-appearance and turnover and lessened performance. Then again, satisfaction of the psychological contract makes sentiments of being esteemed, expands trust, prompts positive results for employee and the organization. Employees who see that their boss has satisfied his/her guarantee may feel more required by the organization and recognize all the more intimately with its qualities (O'Leary-Kelly, et al., 2014).

As indicated by Parzefall, (2008), a breach in the psychological contract occurring when the business does not convey the arrangement significantly affects employee states of mind and conduct. Psychological contract breach can prompt among others diminished trust, declined performance, lessened duty to the association, expanded exit and disregard, less hierarchical citizenship conduct and decreased employee satisfaction. A positive psychological contract then again prompts higher satisfaction with work and with the work life parity and life overall, higher hierarchical duty, bring down worry at work and expanded work inspiration (Orvis, et al., 2008).

\subsection{The new employment relationship}

Contrasts in what employees require and need in an employment relationship are additionally prone to exist crosswise over employees who are at various profession and life stages. Schraeder, et al., 2007, asserts that late graduates are considerably more prone to recognize openings for work as a need. It has likewise been recommended that critical contrasts additionally exist in the coveted employment connections of center versus fringe employees and administrative versus administrative employees. The point to be stressed is that with regards to dealing with the new employment relationship(s), it ought not to be accepted that one size fits all employee organizations (Schraeder, et al., 2007).

Waiganjo \& Ng'ethe (2012) were of the idea that the new employment relationship is portrayed by adaptability in employees and businesses dealings with one another. A longing for adaptability can be found on the two sides of the employment relationship. Organizations confronting expanding rivalry and quick innovative change support, if not, require more prominent adaptability. On the other hand, Suazo (2009) reiterated that because of changing workforce socioeconomics and work esteems, employees progressively want adaptability in their work and non-work needs and interests. The standard of correspondence, thought to be an all inclusive standard, recommends that if an organization anticipates that employees will be adaptable keeping in mind the end goal to address the business' needs, then should offer employees adaptability to address their issues and interests. At the end of the day, adaptability in the new employment relationship ought to be seen as a two-way road, and it would be a great mistake for bosses to treat it generally (Suazo, et al., 2009).

Employee commitment has for quite some time been a worry of organizations in light of its connection to esteemed employee practices, for example, benefit, citizenship, learning, and participation. Committed employees with self-governance of activity will probably adjust their activities to the organization's advantages than employees with self-sufficiency who feels little duty to the organization or its objectives. Without responsibility, even the most talented employees will be of little an incentive to businesses. Luckily for businesses, while the conventional ways to deal with producing responsibility are not as accessible, a large number of the qualities of the new employment relationship have been connected to expanded employee duty: two-way correspondence, participative administration, employee inclusion in basic leadership; sharing of remunerations and hazard; obliging employees' wants for work/non-work life adjust, and giving employees significant, testing work. It very well may be normal that, every single other thing rise to, the fuse of these characteristics into an organization's employment connections will have a tendency to advance employee duty (Xirogiannis,et al., 2007).

It has been accounted for that the utilization of groups, (Rosen, et al., 2009) which have a tendency to include relational associations and social trade among employees, advances employee responsibility. It ought to be noted, in any case, that whether such group related social connection prompts useful responsibility to the organization is probably going to be impacted by various variables that shift from setting to setting (e.g., profitability standards of the work gathering, nature of association from employee viewpoint). At last, it has been contended that responsibility can be advanced by giving employees employability, instead of employer stability and professional success (Parzefall, 2008). The value of this scenario is probably going to rely upon whether the business is giving inside employability or outside employability. Giving employees just firm particular information, aptitudes, and capacities is probably going to be seen as a demonstration of patent boss self intrigue, and therefore, isn't probably going to create any critical level of employee duty. In any case, responsibility ought to be advanced if the business guarantees to give its employees the learning, aptitudes, and capacities expected to stay attractive inside and outside the organization, and afterward conveys on that guarantee. Such a demonstration may flag a guarantee to employees with respect to the organization, which would have a tendency to advance a corresponding responsibility (Rousseau, 2004).

The fruitful administration of the new employment relationship will expect businesses to give more prominent concern for issues of regard and decency for somewhere around two reasons. To start with, deferential and reasonable treatment advances employee full of feeling responsibility (O’Donohue \& Nelson, 2009). Because of 
the unequivocal absence of security and different changes in the employment relationship, employees have turned out to be progressively delicate to issues of regard and reasonableness in the work put. Employees are ending up more farfetched about the degree to which administration considers their interests in choices influencing them, and more incredulous that their bosses are satisfying their commitments. This sort of uncertainty and distrust is probably going to prompt expanded affectability to regard and reasonableness issues, which will require supervisors' extensive focus on regarding maintaining caution from getting to be self fulfilling (Lapalme et., 2011)

Most if not all employees prefer open, honest, two-way communication in any employment relationship because by this, the supervisors are sharing information to authorize the subordinates to invariably assist in decision (Roehling et al., 1998) in the organization's day to day operations. In real sense, and on the other hand, most supervisors appear doubtful about open and reciprocal communication to employees. In most cases, they are more concerned with straying from what the employees parse wants or failing to fulfill their needs and grievances. Mangers at times fail to respond in time or just let it pass without much ado. In that regard, one irony concerning employment relationship focus and remains to appear the single most challenging for business owners to successfully execute (Rosen,.et a.,2009)

In a nutshell, a fruitful management of the new employment relationship will require the human resource experts to viably execute their jobs as managerial master, employee champion, strategic partner and change operator (Rupp, et al., 2014. Specifically, because of the difficulties related with creating and enhancing employee assignments, the comprehensive need to take care of employment related issues, and the perceived significance of open, reciprocal communication among the business owners and employees, the job of employee champion is fast rising against the relative expanded significance. Inspiring organizations to perceive and bolster the significance of the employee defender responsibility, while building up the important specialized and relational aptitudes expected to viably complete it, are challenges HRM officials must be set up to meet (Schreyo“gg, \& Sydow, 2010).

\subsection{Psychological Contract Breach}

Psychological contract breach is the cognition that the organization has failed to fulfil one or more of its obligations. Morrison and Robinson, 1997 cited in Parzefall and Coyle-Shapiro, 2009) and has been distinguished from violation, which captures the emotional response that may arise from breach. A breach that is believed to be intentional has more severe outcomes than a breach that is believed to be caused by environmental factors, or by and honest misunderstanding (Parzefall and Coyle-Shapiro, 2009).

A violation into the Psychological Contract happens when the parties have neglected to convey on what they settled upon. An apparent breach of a psychological contract can adjust an employee's execution and promise to an organization and additionally lead the employee to think about leaving or to really leave an association. Psychological contract breaches are more successive and exceptional in organizations that are scaling down or rebuilding a breach of the psychological contract, results to sub-par execution, belittling, bring down responsibility, non-attendance, and turnover. In the scholarly condition, a psychological contract includes an arrangement of desires by another employee about the guarantees made as a major aspect of the new activity however not formally written in the letter of offer and authority contract. These might incorporate a collegial situation, casual mentorship, starting showing load, staff support, office and research facility space, lab hardware, and time to build up an experiential site. Psychological contract breaches are more extreme than neglected desires in that they cause a sentiment of having been wronged. Moreover, the effect of psychological contract breaches stretches out past frustration and disappointment related with imbalances to incorporate sentiments of disloyalty. Imbalances can normally be helped, however saw breaches of psychological contracts are not all that effortlessly repaired.

According to CIPD (2016), the weight of research indicates that instances of psychological contract breach tend to affect both employee attitudes and behaviours, although the effect is significantly more pronounced on attitudes than behaviours. In particular, breaches in the psychological contract have been found to be associated with the following attitudes: lower levels of job satisfaction; lower levels of organizational commitment; and a greater intention to quit. Breaches have also been associated with several dimensions of adverse employee behaviour: higher quit rates; fewer propensities to display organizational citizenship behaviour ('going the extra mile' at work); and lower in-role job performance.

Hall (2014) argues that given that psychological contracts are implicit, potentially complex and inherently subjective organizations (and employees) should make the terms of these contracts more explicit so that there is less chance of breaches being caused by misunderstanding. This suggests the need for open and honest discussions between management and employees concerning their mutual expectations and perceptions of promises and obligations. It also suggests a role for 'realistic job previews', comprehensive induction programs, wide-ranging performance and development meetings and regular feedback (Hall 2014).

\subsection{Strategic nature of psychological contract}

Organisations put resources into human asset hones, similar to compensation, preparing and advancement, to enhance these relations. The dynamic idea of contemporary employment relations has prompted an accentuation 
on two specific contract terms: the timeframes and execution necessities of the contracts. Two noteworthy sorts of contracts are basic in the work environment (Sheepers, \& Shuping, 2011). When one masterminds these two contract includes in a two-by-two system, one can distinguish four kinds of contracts; relational, balanced, transactional and transitional (Schreyo"gg \& Sydow, 2010).

Rousseau (2008) characterizes the transactional contract as an employment course of action with a here and now or restricted term. It centres basically around: particular, tight obligations, monetary exchanges and restricted labourer inclusion or improvement in the association. The business offers employment for a particular or constrained time and isn't bound to future responsibilities. Freese and Schalk (2008) additionally stress the transactional highlights of psychological contracts. They caution that their highlights look like customary work contracts more intently than psychological contracts do as mental models of employee states of mind and conduct.

As the work environment changes, so does the idea of the relationships among employees and managers. In the new work setting, the casual, psychological contract among workers and bosses-what each expects of alternate - centers on competency improvement, nonstop preparing, and work/life balance (Lavelle, et al., 2009). Interestingly, the old psychological contract was about employer stability and consistent headway inside the firm. In a perfect world, couple of workers expect, or want, long lasting employment in a solitary firm. With little desire for headway, workers feel less dedicated to organizational objectives and more dedicated to their own learning and advancement. The information and technological abilities that employees convey with them to the workplace are transportable and are not lost when another activity is taken. Long periods of scaling back and outsourcing have created time starvation, as in, the sentiment of having excessively to do and too brief period to do it (Lavelle, et al., 2015). So as to stay aware of workloads, numerous workers are spending longer hours at work. Workers are not permitted adaptable hours and work courses of action, (for example, working from home). Those with flex hours have restricted opportunity in regards to when and where to work. By far most of workers need to focus on a particular day to work at home or a particular day to take off in the event that they work according to the organization time restrains for instance, 8.00 am-5.00 pm (Gallagher \& Connelly, 2012).

On the other hand De Jong, et al., (2009) postulated that the transitional sort is a transient contract in which execution necessities are feeble. The transitional contract isn't generally a psychological contract however an intellectual express that mirrors the results of organizational change and advances that are inconsistent with a prior employment contract. It is a breakdown in contracts. It needs duty about future employment and has few or no express execution requests or possibilities. It is a state one finds in organizations that are shutting down. The writing characterizes balanced contracts as particular and open-finished employment courses of action adapted as far as the financial accomplishment of organizations (Guest, 2007). Laborers can build up their professions and to the specialists and organizations contribute extraordinarily to one another's learning and advancement. Execution and commitments to the organizations' upper hand, especially even with changing requests that market weight causes, decide the prizes to laborers. In this sense, they are a greater number of conditions than psychological contracts (Kiewitz, et al., 2009).

The relational contract is an open-finished or feeble assertion that builds up and keeps up a relationship in light of passionate inclusion and budgetary reward. The business resolves to stable wages and long haul employment (Orvis, et al., 2008). The employee is obliged to help the organization and to be faithful and focused on the organization's needs and interests. Rousseau (2008) built up an instrument called the Psychological Contract Inventory (PCI) to gauge the highlights of psychological contracts. It depends on the theoretical system demonstrated before and is grounded in organizational theory and research. In spite of the fact that there are different perspectives about the distinctive sorts of psychological contracts that coincide in employment relationships, this investigation utilized Rousseau's (2008) strategy for surveying one kind of psychological contract in every employment relationship. Balanced contracts are kinds of psychological contracts in view of the monetary accomplishment of organizations and employees' chances to build up their vocations (Sheepers \& Shuping, 2011).

With a specific end goal to change the balanced contracts of employees into relational ones, businesses could think about giving PDIs (Previously disadvantaged individuals) chances to advance to supervisory positions. Specialists with relational contracts have enthusiastic relationships with the organization. They hope to speak to the organization and need to make a positive picture of it (Suazo, 2009). They are actually required with the organization and realize that the organization is additionally worried about their prosperity. Standard correspondence on issues that worry the organization or its employees is fundamental to them. Employees with balanced contracts have faith in profession improvement. Subsequently, correspondence about strategies or changes in approaches is imperative in deciding their vocation designs. These employees will acknowledge new and testing requests for the prosperity of the organization and criticism on organizational execution is vital to them (Aggarwal \& Bhargava, 2008).

\subsection{Human resource practices and psychological contracts}

Human resource practices send very concrete messages about what organizations expect and what employees can 
consequently foresee. They are real systems employees use to comprehend the terms of their employment. Moreover, human asset hones make legally binding and future aims through contracting hones, remunerate hones and formative exercises. Organizations even utilize them as specialized instruments. Human asset hones incorporate giving impartial compensation, perceiving the endeavors and commitments of employees, giving chances to preparing and vocation improvement and forming employees' states of mind and conduct (CoyleShapiro \& Conway, 2004).

The enrollment procedure is the employees' first correspondence with the organization. Along these lines, it impacts their states of mind and conduct fundamentally. Also, Armstrong (2006) underlines the impact of acceptance on employees' view of the organization. New work encounters, intriguing assignments, abilities based preparing in accordance with an organization's business goals and an arranged vocation way additionally flags the organization's goal to cultivate a long haul employment relationship. Human asset rehearses prompt standardizing contracts and influence organizational culture (Dawson, et al., 2014). They, thus, prompt shared demeanors, practices and enhanced organizational execution. In times of retreat, organizations may diminish use on preparing and advancement. In this way, human asset professionals need to take note of the conceivable ramifications of employee devotion and rupturing psychological contracts due to the solid relationship among preparing and improvement and relational contracts (Orvis, et al., 2008).

The current entities may not be successful, not unless their employers consent to add to their main goal and survival. Consequently specialists and businesses need to concede to the commitments that laborers will make to the firm and the other way around. Understanding and viably dealing with these psychological contracts can enable organizations to flourish (Rupp, et al., 2014). Organizations are along these lines progressively recognizing psychological contract as a noteworthy part of employment relationship. The idea of commonality is a noteworthy element of psychological contract, suggesting that there is a typical and concurred comprehension of guarantees and commitments the separate gatherings have made to one another about work, pay, reliability, duty, adaptability, security and professional success (Suazo, et al., 2009).

To guarantee a feeling of individual accomplishment, improve employability and engender relationship esteems with an end goal to keep up a sound psychological contract which will animate responsibility and faithfulness, organizations need to change work designs. For a proceeding and amicable relationship to exist between the employee and the organization, a balanced psychological contract is fundamental (Wöcke \& Sutherland, 2008). In any case, its infringement can flag to the members that the gatherings never again share or shared a typical arrangement of qualities and objectives since as a psychological contract makes feelings and states of mind that shape and control conduct. Administration of organizations has the center errand towards the administration of a psychological contract which has a positive relationship with a scope of results inside the employment relationship and this is a helpful method for conceptualizing that relationship (Parzefall, 2008).

Likewise, Roehling et al., (1998) affirm that compensation and benefits majorly affect the employment relationship from the start. Execution administration rehearses additionally assume enter jobs in deciding employee-boss desires. An organization's business system straightforwardly impacts its employment relationship methodology, which human asset rehearses (like learning and performance management, recruitment, training and development) actualize. On an individual level, these human resource practices greatly influence the employee's comprehension of the employment relationship or psychological contract (Rupp et al., 2014).

The measure of preparing and improvement a business will put resources into employees with relational contracts will decide the measure of unwaveringness these employees have for the organization. It may alternatively give these employees a suspicion that all is well and good (Sheepers \& Shuping, 2011). Dawson, et al., (2014) states that, since organizational assets are generally constrained, spending assets on preparing may tell employees that the organization esteems them and that they are probably going to appreciate long haul or perpetual employment. Supervision and residency are vital traits in setting up relational psychological contracts, thus organizations can profit by advancement programs on supervision. Then again, employees with transitional contracts don't confide in the business. In this manner, they imagine that communication goes for deluding employees purposefully. These employees see methodology and approaches contrarily or as methods for restricting their opportunity. Communicating with these employees may not profit the organization, as the relationship is destroyed (Suazo, 2009).

\section{Conclusion}

Business owners and organizational strategists do emphasize on commitment to the employees, but mostly care less on long-term loyalty which they have always hunted for but no longer offer satisfaction to the later to maintain it. With a specific end goal to win commitment from the modern employees in the modern place of employment, bosses will confront the test of producing another psychological gain that puts less accentuation on security and more on different wellsprings of satisfaction. Evacuation of the customary loyalty-security contract without various backings for new endorsed behaviour can be deciphered as disloyalty by a few employees. A dynamic, all inclusive employment relationship can and in a great way, enhances efficiency and increase overall employee 
satisfaction levels.

Keeping in mind the end goal to meet expanding requests for adaptability, organizations may timid far from building up relationships with employees in view of professional stability and relentlessly rising salary streams. Anyway, despite everything they require the commitment and loyalty of employees to guarantee palatable levels of efficiency. Preparing and ceaseless improvement is a staggering expense alternative in times of low duration commitment and a very portable workforce. A lower cost option might be to expand the potential for characteristic rewards, for example, feeling of accomplishment, acknowledgment, awareness of other's expectations and relationship with associates.

\section{References}

Alcover M. C., Rico R., Turnley W.H. \& Bolino M. C. (2016). Understanding the changing nature of psychological contracts in 21st century organizations: A multiple-foci exchange relationships approach and proposed framework. Organizational Psychology Review 2017, Vol. 7(1) 4-35

Aggarwal, U., \& Bhargava, S. (2008). Reviewing the relationship between human resource practices and psychological contract and their impact on employee attitude and behaviours: A conceptual model. Journal of European Industrial Training, 33(1), 3-41.

Armstrong, M. (2006). A Handbook of Human Resource Management Practice. (10th ed.). London: Kogan Page Ltd.

Chew, J., \& Chan, C.A. (2008). Human resource practices, organisational commitment and intention to stay. International Journal of Manpower, 29(6), 503-522. doi:10.1108/01437720810904194

Coyle-Shapiro, J. A. M., \& Conway, N. (2004). The employment relationship through the lens of social exchange theory. In J. Coyle-Shapiro, L. M. Shore, M. S. Taylor, \& L. E. Tetrick (Eds.), The employment relationship: Examining psychological and contextual perspectives (pp. 5-28). New York: Oxford University Press

Dawson, G. S., Karahanna, E., \& Buchholtz, A. (2014). A study of psychological contract breach spillover in multiple-agency relationships in consulting professional service firms. Organization Science, 25, 149-170.

De Jong, J., Schalk, R., \& De Cuyper, N. (2009). Balanced versus unbalanced psychological contracts in temporary and permanent employment: Associations with employee attitudes. Management and Organization Review, 5, 329-351.

Epitropaki, O. (2013). A multi-level investigation of psychological contract breach and organizational identification through the lens of perceived organizational membership: Testing a moderatedmediated model. Journal of applied psychology

Freese, C., \& Schalk, R. (2008). How to measure the psychological contract? A critical criteria-based review of measures. South African Journal of Psychology, 38(2), 269-286.

Gallagher, D. G.,\& Connelly, C. E. (2012). Rethinking the employee-organization relationship: Insights from the experiences of contingent workers. In M. L. Shore, J. A.-M. Coyle-Shapiro, \& L. E. Tetrick (Eds.), The employee-organization relationship. Applications for the $21 \mathrm{st}$ century (pp. 255-280). London, UK: Routledge.

Guest,D. (2007). Human Resource Management: Towards a new psychological contract. Oxford: Oxford University Press.

Hall, R. (2014). Psychological Contracts: why do they matter? University of Sydney: UK

Jones, D. A., \& Skarlicki, D. P. (2013). How perceptions of fairness can change. A dynamic model of organizational justice. Organizational Psychology Review, 3, 138-160.

Kiewitz, C., Restubog, S. L. D., Zagenczyk, T., \& Hochwarter, W. (2009). The interactive effects of psychological contract breach and organizational politics on perceived organizational support: Evidence from two longitudinal studies. Journal of Management Studies, 46, 806-834.

Lapalme, M.-E., Simard, G., \& Tremblay, M. (2011). The influence of psychological contract breach on temporary workers' commitment and behaviors: A multiple agency perspective. Journal of Business and Psychology, 26, 311-324.

Lavelle, J. J., Brockner, J., Konovsky, M. A., Price, K. H., Henley, A. B., Taneja, A., \& Vinekar, V. (2009). Commitment, procedural fairness, and organizational citizenship behavior: A multifoci approach. Journal of Organizational Behavior, 30, 337-357.

Lavelle, J., Rupp, D., Manegold, J. G., \& Thornton, M. (2015). Multifoci justice and target similarity: Emerging research and extensions. In M.Ambrose \& R. Cropanzano (Eds.), The Oxford handbook of justice in work organizations (pp.165-186). Oxford, UK: Oxford University Press.

Leonardelli, G. J., Pickett, C. L., \& Brewer, M. B. (2010). Optimal distinctiveness theory: A framework for social identity, social cognition, and intergroup relations. In M. P. Zanna \& J. M. Olson (Eds.), Advances in experimental social psychology (Vol. 43, pp. 63-113). San Diego, CA: Academic Press.

Maigure, H. (2002). Psychological contracts: are they still relevant? Career Development International, 7(3), $167-$ 180 
O’Donohue, W., \& Nelson, L. (2009). The role of ethical values in an expanded psychological contract.Journal of Business Ethics, 90, 251-263.

O’Leary-Kelly, A. M., Henderson, K. E., Anand, V., \& Ashforth, B. E. (2014). Psychological contracts in a nontraditional industry: Exploring the implications for psychological contract development. Group \& Organization Management, 9, 326-360.

Orvis, K. A., Dudley, N. M., \& Cortina, J. M. (2008). Conscientiousness and reactions to psychological contract breach: A longitudinal field study. Journal of Applied Psychology, 93, 1183-1193.

Parzefall, M.-R. (2008). Psychological contracts and reciprocity: A study in a Finnish context. The International Journal of Human Resource Management, 19, 1703-1719.

Parzefall, M., \& Coyle-Shapiro, J. (2011). Making sense of psychological contract breach, Journal of Managerial Psychology, 26(1), 12-27

Roehling M., Cavanaugh M., Moynihan L. \& Boswell W. R.( 1998). The Nature of the New Employment Relationship(s): A Content Analysis of the Practitioner and Academic Literatures

Rousseau D. (2004). Psychological Contracts in the Workplace: Understanding the Ties that Motivate. The Academy of Management Executive. 18(1).120-127.

Rosen, C., Chang, C., Johnson, R., \& Levy, P. (2009). Perceptions of the organizational context and psychologicalcontract breach: Assessing competing perspectives. Organizational Behavior \& Human Decision Processes, 108, 202-217.

Rousseau, D.M. (2008). Psychological Contract Inventory: Employer and employee obligations. Pittsburgh, PA: Heinz.

Rupp, D. E., Shao, R., Jones, K., \& Liao, H. (2014). The utility of a multifoci approach to the study of organizational justice: A meta-analytic investigation into the consideration of normative rules, moral accountability, band width fidelity, and social exchange. Organizational Behavior and Human Decision Processes, 123, 159-185.

Schraeder, M., Becton, J.B., \& Portis, R. (2007). A critical examination of performance appraisals. The Journal for Quality \& Participation, 30(1), 20-25.

Sheepers, C.,\& Shuping, J. (2011). The effect of Human resource practices on psychological contracts at an iron ore mining company in South Africa. SA Journal of Human Resource Management 9 (1). 1-19.

Suazo, M. M. (2009). The mediating role of psychological contract violation on the relations between psychological contract breach and work-related attitudes and behaviors. Journal of Managerial Psychology, 24, 136-160.

Suazo, M.M., Martinez, P.G., \& Sandoval, R. (2009). Creating psychological and legal contracts through human resource practice: A signalling theory perspective. Human Resource Management Review, 19, $154-166$. doi:10.1016/j. hrmr.2008.11.002

Schreyo“gg, G., \& Sydow, J. (2010). Organizing for fluidity? Dilemmas of new organizational forms. Organization Science, 21, 1251-1262

Waiganjo E.W \& Ng'ethe J. M.(2012). Effect of Human Resource Management Practices on Psychological Contract in Organizations. International Journal of Business and Social Science. Vol. 3 No. 19.

Wöcke, A., \& Sutherland, M. (2008). The impact of employment equity regulations on psychological contracts in South Africa. International Journal of Human Resource Management, 19(4), 528-542.

Xirogiannis, G., Chytas, P., Glykas, M., \& Valiris, G. (2007). Intelligent impact assessment of HRM to the shareholder value. Retrieved September 20, 2009, from www.sciencedirect.com 